\title{
EXAMINING THE ETHICAL PREDISPOSITION OF THE NEXT GENERATION OF BUSINESS LEADERS IN ChINA AND THE Republic of South Africa
}

\author{
Sam Fullerton \\ Department of Marketing, Eastern Michigan University, USA \\ Christo Bisschoff \\ Business School, North-West University \\ David L Moore \\ Department of Marketing, Le Moyne College, USA
}

\begin{abstract}
This study was undertaken in an effort to determine the attitudes of business students in South Africa and China toward a battery of questionable actions undertaken by anonymous business entities. In general, practices such as the outsourcing of labour and celebrity endorsements met with little opposition on the part of the students. Conversely, actions such as the shipment of unsafe products to overseas markets and a doctor smuggling a potentially beneficial (but illegal) drug across international borders in an effort to help a patient were strongly condemned. A comparison of the means of the 14 scenarios resulted in statistically significant differences for the two countries on eight of the questionable actions. In seven of the eight, the South Africans exhibited stronger opposition (or a lower level of support for) the behaviour of the organization. Furthermore, the grand means for the two countries also favored the RSA as the country with the higher ethical predisposition.
\end{abstract}

JEL D83, 84

\section{1}

\section{Introduction}

In an era of business characterised by international expansion, marketers have begun to target geographic locations that were previously largely ignored. In this regard, some observers might offer the standard cliché that the world has become smaller. With better communications tools and more efficient modes of transportation, marketers do indeed enjoy greater access to these previously impenetrable markets. So too, the emergence and expansion of multilateral trade alliances such as the North America Free Trade Agreement (NAFTA) and the European Union (EU) have resulted in more marketers adopting an international perspective. Yet another contributing factor is the general fall of Communism, a historic development that led to the reunification of Germany and the opening of a multitude of new markets. The corresponding new emphasis on entrepreneurial activities in the former Communist bloc has accompanied the ongoing transition to a marketdriven economy (Du \& Tang, 2005). Eastern Europe and China represent but two examples of this evolutionary process. Political barriers are also being dismantled; the most noteworthy is the metamorphosis of South Africa which has opened the doors to new opportunities as a direct result of the abolition of apartheid. Finally, the general reductions in tariffs that constituted the early focal point of the World Trade Organization's (WTO) predecessor, the General Agreement on Tariffs and Trade (GATT), has led to more open trade in the 
international community. As the crossing of borders has become less encumbered by a myriad of trade barriers, marketers across the globe have sought to take advantage of the resultant emerging opportunities.

With the trend of corporate acquisitions and mergers, it is becoming difficult even to identify the home country of any marketing entity. Is Jaguar an American or a British vehicle? How many laypersons know that Miller Beer is now owned by South African Breweries (SAB)? Are consumers aware of the fact that IBM's laptop computer operations were acquired by an emerging company in an emerging economy - Lenovo in China? So while the world is not physically shrinking in size, to multinational marketers such as those just mentioned, it may well appear to be the case.

Global expansion is accompanied by an increased level of risk. Practices that have been accepted in one country may be deemed inappropriate in another. For example, the use of sexuality in the marketing of fragrances raises few eyebrows in France. Yet a similar promotional strategy used in Kuwait would most likely be subjected to considerable criticism and result in a consumer backlash that would ultimately prove detrimental to the marketer. As a result of this increased risk, marketers must acknowledge the need to consider adapting their strategies so as to conform to the norms and social mores of the host countries in which they operate or otherwise maintain a meaningful presence. After all, it is this combination of international operations and ethics that has been characterised as the most difficult task facing today's marketers (Velasquez, 2000; Vogel, 1992). And when entering into the less developed economies, the lack of knowledge as to what constitutes unethical behaviour simply serves to ratchet up the difficulty and the inherent risk. Two such emerging economies are China and, to a lesser extent, the Republic of South Africa.

This study will seek to help marketers gain a better understanding of the ethical predisposition of business students in these two countries. It is these students who are the future leaders of industry and commerce as these two economies continue to expand within the global arena.
As in any nation, it is a tenuous presumption that a singular culture exists to which all of its inhabitants conform. Yet a multitude of studies purport to measure that precise phenomenon. To illustrate this point, consider the vast array of studies that have included the United States in an effort to evaluate a population's overarching ethical predisposition despite the presence of a number of significant subcultures, including the Caucasian/European, African American, Hispanic, and Asia American segments. This same argument is appropriate in regard to the two countries under scrutiny in this study. The Republic of South Africa, for example, is most notably culturally stratified on the basis of race. But even an examination of the Black majority would document differences in language, customs, and social mores. Similarly, China has been deemed to comprise several sociolinguistic subcultures as well as four regional subcultures, namely those of Beijing, Hong Kong, Taiwan, and Wuhan (Huo \& Randall, 1991). Further cultural variation has been associated with metropolitan versus rural dwellers as well as old-school Communist supporters versus new school market-reform minded groups.

Thus, it is not unreasonable for academics and practitioners to question the efficacy of conducting research which presupposes that each country can be described on the basis of a single overarching mindset. In addressing this concern, it is important to recall that this study focuses on university business students, not the broad population. Furthermore, recent research into social identity theory has demonstrated that students tend to adopt an ethical mindset which they believe conforms to the standards that they presume the role models in their aspiratory reference groups possess (Neale and Fullerton, 2008). Thus, it can be argued that business students gravitate towards a homogeneous mindset irrespective of subcultural dynamics.

2

\section{Literature review}

The literature provides ample support for Velasquez' (2000) assertion that the combination of international operations and business ethics represents a difficult amalgamation for today's 
marketers. Compounding this dilemma is the reality that some international ventures are undertaken in countries where free enterprise is a comparatively new mode of operation. Yet it is these emerging economies that represent perhaps the most significant growth opportunities for today's marketers. In this respect one common approach to developing a better understanding of a country's ethical inclinations is through a better understanding of the dominant cultural traits. Culture has been characterised as the collective programming of the mind which distinguishes the members of one human group from another (Hofstede, 1980). As such, it is intricately tied to attitudes and behaviour.

\subsection{China's cultural underpinnings}

It has been reported that little research has been carried out into "future managers," that is to say the students who are currently enrolled in the study of business in these emerging markets (Ahmed, Chung \& Eichenseher, 2003). But since individuals in less developed countries tend to possess lower expectations regarding adherence to ethical standards of conduct, social responsibility, and legal statutes (Shafer, Fukukawa \& Lee, 2006), there is an obvious need to explore the ethical predisposition of those people in these emerging markets. An abundance of literature confirms the designation of both China and South Africa (Atkins, Chung \& Schieritz, 2007; Norton, 2007; Anonymous 2006b) and the Republic of South Africa (Atkins, Chung \& Schieritz, 2007; Anonymous, 2006a; Rossouw, 1994a) as emerging markets although there is also evidence to support the premise that South Africa's state of development exceeds that of China. China's GDP of USD\$ 7.043 trillion makes it the world's second largest economy; however, when scrutinising the 2007 per capita GDP, the USD\$ 10,600 measure for the Republic of South Africa is double the USD \$ 5,300 generated in China. Furthermore, the goods and services sectors account for 89 per cent of the Chinese GDP whereas the comparable measure for the RSA is 97.3 per cent. The CIA World Fact Book further cites China's gradual emergence from a centrally planned economy, starting with reforms in the 1970s and the phasing out of collective agriculture. This compares to the characterisation of the RSA as a middle-income emerging economy with well developed financial, legal, communications, energy, and transportation sectors that is home to the world's $17^{\text {th }}$ largest stock exchange, a modern infrastructure, and macroeconomic stability (World Factbook, 2008). Thus, it can be reasonably stated that the RSA economy is at a higher state of development than the Chinese economy.

Based on a premise articulated by Shafer, Fukukawa, and Lee (2006), one would expect South Africans to exhibit a higher ethical predisposition than their Chinese counterparts. Rudimentary support for this assertion was offered by Khera (2001) in his comparison of Eastern and Western societies. Although China is not a microcosm of Eastern Europe, its philosophical and economic similarities with the old Soviet Union and the Eastern European paradigm allow China to be characterised as an Eastern nation. Likewise, South Africa is many kilometres from Western Europe and North America, yet its economic and cultural ties, particularly with the UK, allow it to be placed within the Western domain despite the variations indigenous to its multicultural, multilanguage populace that reflects considerable heterogeneity across an array of subcultures. Thus, if we classify countries based upon an East-West dichotomy, China better fits the Eastern designation whereas South Africa is better placed within the Western context.

While citing blatant corruption in the East, Khera (2001) referred to the West as being perceived to be being more ethical, albeit he went on to state that perhaps the more favourable perception could be traced to the West's acumen in concealing its breaches of ethical conduct. This comparison is relevant since the East-West dichotomy is closely aligned with measures that differentiate between lessdeveloped and more-developed countries.

Despite this type of assertion, there are cultural dynamics that would seem to favour China in terms of the ethics scorecard. In a study by Hofstede and Bond (1988), the authors referred to the cultural underpinnings of Confucian 
Dynamism as a long-term orientation that features persistence, reliability, the ordering of relationships, thrift, a sense of shame, tradition, and reciprocity. Similarly, when engaging in any activity in China, one must recognise the role of guanxi, a cultural phenomenon whereby Chinese embrace personal relationships that are characterised by favour, trust, and interdependence (Wong \& Chan, 1999). To some, guanxi is similar to the Western concept of relationship marketing (Lovett, Simmons \& Kali, 1999). However, while Confucian Dynamism and guanxi would seem to foster ethical behaviour, such might not be the case. It has been argued that each tends to emphasise personal relationships whereby the individual's behaviour is based, not on ethics or law, but on the ability to perpetuate a more meaningful relationship than any that is maintained within the business environment. Advancing a similar argument was Woodbine's (2004) assertion that the "collectivism" which dominates Chinese culture actually fosters unethical behaviour. This is consistent with an earlier assertion of Vitell, Nwachukwu, and Barnes (1993). Based upon the theoretical premises just articulated, it should not be surprising to see authors who characterise the decision-making process in China as displaying a mixed influence of traditional Confucian values and an emerging market ethic (Whitcomb, Erdener, \& Li, 1998). The theoretical constructs seem to convey the warning caveat emptor, but how does that compare with reality?

\subsection{China - empirical studies}

A significant amount of literature focuses on China. In general, it does not place the country in a favourable light. He (1998) noted that the high incidence of corruption in China may have led to the acceptance of such behaviour, thereby making legal and moral transgressions seem less controversial. Shortly after this assessment, Khera (2001) spoke of the "special mafia's" debilitating impact on the Chinese economy while also pointing to China's propensity to exploit its own natural resources in favour of short-run benefits. Shortly thereafter, Tam (2002) indicated that the Chinese environment was rife with a myriad of breaches of ethical standards of conduct. In this regard, according to Chen and Chen (2005) there are several factors leading to this decline. Among them are the absence of any clear standards of conduct, high levels of distrust (contrary to guanxi), a weak legal system, and ineffective management systems. Eight years after He's (1998) earlier explanation, Pederson and Wu (2006) stated that China is still considered to be one of the most corrupt countries in the world. Similarly, Shafer, Fukukawa, and Lee (2006) cite reports which imply that the move to a market-driven economy has led to a general decline in the standards of conduct. Their premise runs counter to an earlier assessment by Enderle (2001) who asserted that marketing would play a pivotal role in China's reform. In line with Enderle's argument, it has been noted that there are signs of convergence which document a closing of the ethics gap between China and the more industrialised West (Wright et al., 2006). However, the empirical evidence up to the present does not offer substantive support for the premise of a narrowing gap.

Previous research tends to support the premises delineated in the evaluation of the normative perspective. Du and Tang (2005) surveyed Chinese students; among their findings were that financial rewards constituted a key motivating factor which led business students to accept actions that were less likely to be embraced by the general Chinese student population. Still, it was noted that the Chinese students' rating on the "Corruption Perception Index" measured in the study was low, especially in comparison to students in other countries. Wright, Szeto, and Lee (2003) concurred that the long-standing guanxi traditions were being eroded since capitalism has changed the Chinese mindset to one that focuses on individual achievement and advancement. As such, the respondents in that study downplayed the negative effects of corruption and bribery. The statistics are compelling, since fully 40 per cent agree with the statement that corruption and bribery do not adversely affect China's international image. Concurrently, 38 per cent indicated that they saw no need for any new laws designed to prevent unethical behaviour from taking place. The 
study also purportedly measured practitioners' attitudes so as to establish a benchmark by which future businesspeople can be compared. It also provided the basis for an assessment of the changes that had occurred over a five year period. Approximately 60 per cent of those surveyed indicated that their personal ethics had not changed over the past five years. The sample exhibited a high level of polarisation that clouded the ability of the authors to draw conclusions from the results. While they could not conclude that improvement had occurred, one conclusion was that it had not worsened. Another study indicated that Chinese students are less idealistic than their Western counterparts, so they exhibit less concern about the environment and the welfare of others (Whitcomb, Erdener \& Li, 1998). Similarly, according to Jackson et al. (2000) the highly relativistic approach to decision making with no moral absolutes means that ethics are often dictated by the situation in which the decision maker is placed.

With the Summer Olympics coming to Beijing in 2008, a major concern articulated by the International Olympic Committee (IOC) involves the safeguarding and protection of intellectual property rights. New laws that involve potential prison terms for violators were passed in an effort to protect the trademarks owned by the IOC. To illustrate the extent of the problem caused by counterfeit goods, consider the following. Cheung and Prendergast (2006) reported that "China has built a reputation as the source" of counterfeit goods; in fact more than 60 per cent of all counterfeit goods seized by U.S. customs agents in 2003 were produced in China. The counterfeiters also have the advantage of a brisk market at home even though buyers fully expect the knockoffs to be of lower quality than the originals. Among the most common counterfeits are computer and entertainment software, clothing, pharmaceuticals, and auto parts. It has been estimated that the Chinese knockoffs cost American business enterprises \$2 billion per year (Berrell \& Wrathall, 2007) while also creating potential safety hazards for those consumers who purchase crucial, but inferior, products such as pharmaceuticals and auto parts. Berrell and Wrathall add that the
Confucian traditions inherent in the Chinese culture have made piracy of intellectual properties an acceptable practice. Batson (2006) indicates that the problems involving items of intellectual property are still significant, but that they are lessening. Still, the problems are enough to exacerbate an increasingly hostile trade environment.

Numerous cross-cultural studies have included China as one of the countries under scrutiny. Shafer, Fukukawa, and Lee (2006) found that Americans scored higher on Hofstede's "individualism" scale and lower on "Confucian dynamism". These findings are consistent with the general consensus that behaviour that might be deemed unethical is more likely to occur in China. Yet this same study documented results that led the authors to conclude that the Chinese more strongly support the belief that ethical conduct is a prerequisite for business success. A study by Ahmed, Chung, and Eichenseher (2003), in comparing students in China, the United States, Egypt, Finland, Korea, and Russia, found that the Chinese students scored lower on the measure of ethical predisposition. As the authors further noted, the Chinese students indicated their belief that little harm resulted from an array of questionable behaviours. Furthermore, they tended to view ethics and profitability as somewhat incompatible constructs. However, at least one study offered positive results. In a comparison of China, the United States, and Jamaica, the results indicated that there were no significant differences between China and the United States while Jamaica ranked last in the assessment of five vignettes employed to measure attitudes towards questionable actions on the part of business (Fok, Hartman \& Kwong, 2005). This study was a replication of one undertaken ten years earlier, and it provided some support for the premise that the ethics gap between China and the West is slowly shrinking.

Obviously, there are significant concerns associated with operating in China. The underlying cultural norms paint an inconsistent picture of the business environment. The empirical evidence documents abuses that often cross the boundary of ethics into the realm of illegality. The literature does, however, appear 
to provide rudimentary evidence of a gradual narrowing of the ethics gap. One example is a survey of members of the American Chamber of Commerce and the U.S.-China Business Council in which approximately one-third of the respondents indicated their belief that there had been an improvement in the protection of intellectual property rights. Furthermore, to quote the U.S. Secretary of Commerce, Carlos Gutierrez, "there is no question they have made progress" (Batson, 2006).

\subsection{South Africa's cultural underpinnings}

Ironically, despite its standing as being further advanced than China, the literature concerning South Africa is comparatively sparse and relatively dated. Perhaps the anxiousness to scrutinise China can be attributed to its recent admission to the World Trade Organization or the sheer magnitude of its market potential. Much of the research into South African ethics is tied to Hofstede's assessment of cultural dimensions in society. Therefore, South African behaviour is often positioned as consisting of expectations based upon theoretical underpinnings.

Over a decade ago, Rossouw (1994b) referred to the Republic of South Africa as a "developing country" while noting that the "struggle for survival in a new South Africa economy...cannot afford morality". As such, there appeared to be a cultural mindset that ethics might succumb to questionable actions if consumers and business enterprises were to survive and prosper in the long run. Shortly thereafter, Rossouw (1997) noted that this was truly a society in transition, one that had encountered a substantial ethical stumbling block. Similarly, van Zyl and Lazenby (1999) stated that the "South African business world is increasingly characterized by the absence of clear ethical norms and behaviours". Statements by others are equally compelling. The president at the time, Nelson Mandela, opined at an opening session of the South African Parliament that "corruption in many forms has deeply infected the fibre of our society" (Rossouw, 1997). At the same time, a South African newspaper editorialised about "the reducing level of ethics" within the South
African business community (Daily News, 1997). In part, Rossouw (1997) blamed the fact that South Africa's exclusion from many global activities because of sanctions tied to apartheid meant that more nefarious business tactics had been required. Thus, what others might view as questionable actions are now deemed both acceptable and justifiable by many South Africans. Factors such as these prompted a call for the King Committee to develop guidelines for a uniform "code of conduct setting out best business practices, including ethical practices in all business enterprises...so as to enhance standards of ethics in business [p. 297]" (Rossouw, van der Watt \& Malan, 2002). In other words, there was a perceived need on the part of the members of the King Committee to increase the level of scrutiny placed on corporate governance.

Singhapakdi, Higgs-Kleyn, and Rao (1999) found that South African marketers are more idealistic and less relativistic than their American peers. The implications of these findings are intriguing. High levels of idealism indicate that the individuals concerned seek altruistic solutions in order to avoid harming others; a lower relativistic outcome is associated with people who are more likely to accept moral absolutes that universally govern right and wrong behaviour (Schlenker \& Forsyth, 1977). Thus, these findings support the premise that South African standards of conduct are higher than those exhibited by Americans. Despite this early endorsement of South Africa, overall, the conceptually-based literature paints a somewhat negative portrait. But what does the empirical research indicate?

\subsection{South Africa - Empirical studies}

In a study of South African business students, Moore and Radloff (1996) noted that the students believed change would be slow and that it might well be years before the significant ethics gap closed in any appreciable way. Furthermore, students articulated their belief that the profit motivation may well supersede social mores and legal statutes and that existing laws offered insufficient disincentives for unethical behaviour. But, despite these two deficiencies, 
the business community's ethical predisposition was evolving in a positive manner. In fact, this study reported that attitudes among American, Australian and South African students exhibited more similarity than disparity.

A recent study of corporate governance focused on the African continent. The authors concluded that the prevailing attitude was that "business ethics are considered an integral and essential part of good governance. From the various codes of corporate governance that were analysed, it is clear that standards of good governance are intertwined with high standards of business ethics". Even greater improvement is anticipated since a second generation of codes for corporate governance has begun to emerge (Rossouw, 2005). Clouding the ability to draw broad generalisations regarding the South African population are the findings of Marta, Singhapakdi, and Higgs-Kleyn (2001) who documented significant differences among the various subcultures (e.g. English, Afrikaans, Zulu, Xhosa, and Tswana) within the South African population. Also contradicting the aforementioned study are the results stemming from an examination of gainfully employed students in the United States, Singapore, and South Africa which found that lower measures of honesty were associated with the South Africans (Klein, 1999).

The varied results emanating from studies performed in South Africa make the drawing of conclusions with regards to the country's ethical predisposition dubious at best. As such, they serve to reinforce the need to engage in further research in an effort to clarify the ambiguities and better understand the inclinations of South Africa's emerging population of business leaders.

\section{3}

\section{Objectives}

There are three basic objectives for this research endeavour. First, the task of developing an "ethical profile" for the future captains of industry in the Republic of South Africa. Similarly, the second objective is to develop an "ethical profile" for the corresponding Chinese segment. With the two profiles completed, the third objective involves the identification of any ethics gaps between the two countries.

\section{4}

\section{Methodology}

Using an earlier instrument designed by Fullerton (1993), business students were asked to indicate their opinions regarding 14 questionable behaviours undertaken by a variety of anonymous business entities. In this regard, it should be noted that the survey as developed by Fullerton (1993) was designed to encompass an array of behaviours for which uniformity of opinion was neither anticipated nor sought. Some of these behaviours are legal (e.g. athlete endorsements) whereas others are not (e.g. false sale prices). Some are highly controversial in some countries and to some individuals (e.g. outsourcing) while the perception of certain actions (e.g. exporting unsafe products to foreign markets) produces relatively uniform responses. It is this diversity of opinion that makes the assessment of markets defined on the basis of national boundaries as well as specific segments within a country relevant.

As is common in ethics research, the respondents were asked to indicate the level of acceptability or unacceptability for a specific scenario which depicts a potential ethical dilemma. These 14 scenarios focused primarily on marketing, but covered a number of business disciplines including marketing (post-disaster pricing), accounting (transfer pricing), and management (outsourcing labour). The measurement scale used was a balanced six-point itemised rating scale. The survey was translated or otherwise edited so that the language, examples, and wording were appropriate in each country. Since business students represented the study's target population, data were collected by administering the survey in one or more core courses in the business schools at universities in each of the two countries. Upper division and core courses were selected because they provided access to students across the range of majors in different business disciplines at each university while concurrently reducing the likelihood of including non-business majors since they were not part of the target population that the sample was designed to represent. 
Analysis using SPSS was employed to achieve the primary research objectives germane to this project: profiling and the assessment of cross-cultural differences. Profiling was achieved via the use of simple descriptive statistics (DESCRIPTIVES) that allowed for the development of a snapshot of the respondents from each country. The grand mean for each country was calculated as the basis for developing a single aggregate measure by which the ethical predisposition of the two samples could be compared. The assessment of cross-cultural differences was operationalised by applying the traditional t-test, using .05 as the critical value of alpha for the rejection of the null hypotheses of equal means for the 14 scenarios. While the type of rating scale used in this study is deemed by many to be interval in nature thus allowing the use of parametric statistics, some may take issue with this assertion. In an effort to alleviate this concern, appropriate nonparametric analyses were used, working with the premise that the data are at least ordinally scaled. In order to identify acceptable and unacceptable practices, percentage distributions were used in lieu of item means. So as to evaluate the presence of differences between the two countries, a chisquare test of independence was employed.

\section{5}

\section{Results}

The initial wave of data collection resulted in usable samples of 88 Chinese and 134 South African business students. Prior to addressing the research objectives, there was a need to assess the comparability of the samples from the two countries. Table 1 documents the fact that while there are modest anecdotal differences when compared on the basis of gender, age, and citizenship, there are no pronounced differences which would preclude the comparison of the South African and Chinese segments.

Table 1

Sample characteristics

\begin{tabular}{|ll|c|c|}
\hline \multirow{2}{*}{\multicolumn{2}{|c|}{ Category/Level }} & \multicolumn{2}{c|}{ \% in Category } \\
\cline { 3 - 4 } & Male & China & RSA \\
\hline \multirow{2}{*}{ Gender } & Female & 69.3 & 66.4 \\
& Under 21 & 30.7 & 33.6 \\
\hline \multirow{2}{*}{ Age } & $21-25$ & 1.1 & 0.0 \\
& Over 25 & 14.8 & 10.1 \\
& Citizen & 84.1 & 89.9 \\
\hline \multirow{2}{*}{ Citizenship* } & 96.6 & 92.6 \\
& Foreign & 3.4 & 7.4 \\
\hline
\end{tabular}

* Citizenship based on being a citizen of the specific country where the survey was administered

The initial objective was to develop a snapshot of the ethical predisposition of the South African students, so we will begin by examining the mean responses for each of the 14 scenarios. For this analysis, a six-point scale was used; thus any item mean exceeding 3.5 would be deemed to fall on the unacceptable side of the scale. For the South African sample, eight scenarios exhibited sample means which indicated that the described behaviours were unacceptable. It was the exporting of unsafe products to overseas markets that met with the greatest disdain $(0=$ 4.97). Of the remaining scenarios, two produced mean values between 4.0 and 5.0, or what would be characterised as moderate disapproval. The items were those of a doctor smuggling an illegal pharmaceutical product home with the belief that the drug would benefit the patient $(0=4.79)$ and the retailer's practice of attempting to "sell up" from an advertised special $(0=4.26)$. Table 2 identifies the behaviours and summarises the results for the eight unacceptable practices. 
Table 2

Unacceptable practices in South Africa

\begin{tabular}{|c|l|c|c|}
\hline Rank & \multicolumn{1}{|c|}{ Behaviour } & Mean* & \% unacceptable \\
\hline 14 & Unsafe products exported to overseas markets & 4.97 & 87.7 \\
\hline 13 & Doctor with illegal pharmaceutical for patient & 4.79 & 82.9 \\
\hline 12 & Selling-up from advertised special & 4.26 & 67.8 \\
\hline 11 & Not placing sold sign on sold house & 3.90 & 54.9 \\
\hline 10 & Criticize competitor by name in a comparison ad & 3.88 & 55.2 \\
\hline 9 & Higher prices by retail chain in poor urban markets & 3.78 & 56.5 \\
\hline 8 & False sale - manipulating prices & 3.59 & 50.5 \\
\hline 7 & Post-disaster increases in prices of needed products & 3.57 & 53.2 \\
\hline
\end{tabular}

* Scale Specifics: 1 = Acceptable; $6=$ Unacceptable; $3.5=$ Scale midpoint

The remaining six scenarios produced mean scores on the acceptable side of the scale $(0<$ 3.50) for the South African sample. The most broadly accepted action, as evidenced by a mean of 1.97, was that of outsourcing production to a low-cost country. It was the only action that produced a mean score of less than 2.0 for the South African sample. Next on the list of acceptable practices is that of using famous athletes as endorsers of consumer products $(0=2.31)$. The third most tolerated behavior, albeit with a substantially lower acceptance rating $(0=2.74)$, is an exclusive distribution agreement for a retailer to be the only one to sell a manufacturer's desirable product in a given geographical market. Table 3 provides an overview of the six acceptable practices identified by the South African respondents. Also noteworthy is the fact that the percentage distributions coincide with the mean-based assessment in the categorisation of acceptable versus unacceptable actions.

\section{Table 3}

Acceptable practices in South Africa

\begin{tabular}{|c|l|c|c|}
\hline Rank & \multicolumn{1}{|c|}{ Behaviour } & Mean & \% acceptable \\
\hline 1 & Foreign outsourcing of production & 1.97 & 87.7 \\
\hline 2 & Product endorsement by famous athletes & 2.31 & 79.7 \\
\hline 3 & Exclusive distribution in retail trade area & 2.74 & 71.0 \\
\hline 4 & Delay new product entry until old inventory Is sold & 2.81 & 70.9 \\
\hline 5 & Advertise (to kids) for toll phone call to Santa Claus & 2.92 & 66.1 \\
\hline 6 & Transfer pricing to minimise income tax obligation & 3.36 & 55.1 \\
\hline
\end{tabular}

The final measure for the South African snapshot is the grand mean for the 14 scenarios. The result of 3.49 falls just shy of the exact midpoint of the rating scale. Although, at face value, the sample mean does fall slightly to the acceptance side of the scale, we prefer to categorise it as a neutral position. As such, acceptance of the array of questionable behaviours is best classified as situational.

For the Chinese sample, the mean response exceeded the neutral midpoint of 3.5 for six of the 14 scenarios. The strongest opposition was 
voiced for the act of shipping dangerous products to overseas markets where consumer protection or product safety laws are somewhat lax, thereby allowing the company to sell the potentially hazardous products outside of its home country $(0=4.82)$. Second on the list of unacceptable behaviours was that of a retailer temporarily raising prices, then lowering them back to their original level a few days later and advertising them as sale prices $(0=4.43)$. The third most strongly criticised practice $(0=4.20)$ was that of a physician smuggling a pharmaceutical product that is illegal in the doctor's home country (but legal elsewhere) back home to dispense it to a patient whom the doctor believes would benefit from using the drug. Table 4 delineates the summary statistics for the six unacceptable practices as identified by the Chinese respondents.

Table 4

Unacceptable practices in China

\begin{tabular}{|c|l|c|c|}
\hline Rank & \multicolumn{1}{|c|}{ Behaviour } & Mean & \% unacceptable \\
\hline 14 & Unsafe products exported to overseas markets & 4.82 & 71.3 \\
\hline 13 & False sale - manipulating prices & 4.43 & 75.0 \\
\hline 12 & Doctor with illegal pharmaceutical for patient & 4.20 & 68.2 \\
\hline 11 & Not placing sold sign on sold house & 4.00 & 63.6 \\
\hline 10 & Selling-up from advertised special & 3.93 & 59.1 \\
\hline 9 & Post-disaster increases in prices of needed products & 3.52 & 52.3 \\
\hline
\end{tabular}

The eight remaining items all exhibited outcomes that are characterised as acceptable based on means below the 3.5 midpoint of the scale. The practice that met with little opposition in China was that of outsourcing manufacturing to a lowcost foreign country $(0=1.43)$. Close behind was the aforementioned strategy of granting exclusive distribution rights to a single retailer within a given geographic market for a desirable product $(0=1.59)$. One other practice, that of using popular athletes as product spokespersons, resulted in an average response of less than 2.0
$(0=1.77)$. Table 5 provides an overview of how the Chinese respondents perceived the acceptability of these eight business practices. It is evident that even though these eight behaviours are all classified as acceptable, there is meaningful variation across the eight items. In other words, some actions are deemed to be more acceptable than others. As was the case with the South African analysis, the percentage distributions coincided with the mean-based analysis in the effort to differentiate between acceptable and unacceptable actions.

Table 5

Acceptable practices in China

\begin{tabular}{|c|c|c|c|}
\hline Rank & Behaviour & Mean & $\%$ acceptable \\
\hline 1 & Foreign outsourcing of production & 1.43 & 95.5 \\
\hline 2 & Exclusive distribution in retail trade area & 1.59 & 93.2 \\
\hline 3 & Product endorsement by famous athletes & 1.77 & 95.3 \\
\hline 4 & Delay new product entry until old inventory is sold & 2.16 & 88.6 \\
\hline 5 & Transfer pricing to minimise income tax obligation & 2.52 & 70.5 \\
\hline 6 & Advertise (to kids) for toll phone call to santa claus & 2.66 & 68.2 \\
\hline 7 & Higher prices by retail chain in poor urban markets & 3.18 & 61.4 \\
\hline 8 & Criticise competitor by name in a comparison ad & 3.48 & 52.3 \\
\hline
\end{tabular}


The final measure used to capture the concept of ethical predisposition was attained by calculating the grand mean of the responses for the 14 scenarios. The resultant value of 3.12 indicates a general level of acceptability of the questionable behaviours. This now leads us to the third research objective, that of comparing the ethical profiles of the two countries.

At face value, the two grand means provide fundamental support for the belief that South Africans display a stronger ethical predisposition than do their Chinese counterparts. Table 6 further documents the differences between the two countries. Overall, for the 14 scenarios, only six exhibited results whereby the hypotheses of equal means could not be rejected. Of the eight where statistically significant differences were documented, the South African respondents exhibited higher standards of conduct for seven. In only one situation, that of temporarily raising prices so as to falsely advertise a sale, did the Chinese sample exhibit more disdain. Still, it should be noted that the absolute difference was very large, thus indicating a much stronger rejection of that particular action. The South Africans exhibited a stronger ethical predisposition in regard to the following behaviours (in descending order based on measured differences): exclusive distribution, transfer pricing, delayed product entry, higher prices in urban stores, a doctor's smuggling of a pharmaceutical, athlete endorsements, and the outsourcing of production. In addition to the eight scenarios, the difference in the grand means which also favoured the South Africans was statistically significant.

When the chi-square test of independence measures were calculated in an effort to validate the t-test results, two additional statistically significant differences were noted. Despite the very small difference in the group means, the Chinese were deemed to be more critical of the realtor who fails to display a sold sign on a house that has in fact already been sold. Conversely, the South Africans were deemed to be more critical of comparison advertising. More importantly, each of the eight scenarios that exhibited statistically significant differences on the t-tests was further supported by the chi-square statistics. Table 6 also provides the measures of significance associated with the chisquare analyses for those readers who prefer to treat the rating scale as ordinal data. However, the authors' perspective is that the rating scale produces interval data, thereby making the t-test the more powerful procedure for the task of identifying statistically significant differences. Therefore, the discussion from this point forward will focus solely on the t-test results.

Table 6

Comparison of means - South Africa and China

\begin{tabular}{|l|c|c|c|c|c|}
\hline \multirow{2}{*}{\multicolumn{1}{|c}{ Behaviour }} & \multicolumn{3}{c}{ Means } & \multicolumn{2}{c|}{ Stronger } \\
\cline { 2 - 6 } & RSA & China & sig. & Opposition* & $\chi^{2}$ sig. \\
\hline Exclusive distribution & 2.74 & 1.59 & .000 & South Africa & .000 \\
\hline Selling up & 4.26 & 3.93 & .176 & - & .086 \\
\hline Post-disaster pricing & 3.57 & 3.52 & .827 & - & .120 \\
\hline Higher urban prices & 3.78 & 3.18 & .018 & South Africa & .017 \\
\hline Athlete endorsements & 2.31 & 1.77 & .003 & South Africa & .020 \\
\hline Delayed new product entry & 2.81 & 2.16 & .002 & South Africa & .031 \\
\hline Unsafe products exported & 4.97 & 4.82 & .455 & - & .212 \\
\hline No sold sign on sold house & 3.90 & 4.00 & .661 & - & $.005^{* *}$ \\
\hline Transfer pricing - tax shift & 3.36 & 2.52 & .000 & South Africa & .000 \\
\hline Smuggling pharmaceutical & 4.79 & 4.20 & .009 & South Africa & .022 \\
\hline
\end{tabular}




\begin{tabular}{|l|c|c|c|c|c|}
\hline Advertise Santa phone call & 2.92 & 2.66 & .319 & - & .084 \\
\hline Outsourcing of production & 1.97 & 1.43 & .002 & South Africa & .016 \\
\hline Comparison advertising & 3.88 & 3.48 & .111 & - & $.000^{* *}$ \\
\hline Artificial sales prices & 3.59 & 4.43 & .000 & China & .000 \\
\hline Grand mean & 3.49 & 3.12 & .000 & South Africa & N/A \\
\hline
\end{tabular}

* May be characterized as weaker support where means are below the 3.5 threshold

** Contradictory results from t-tests and chi-square tests of independence

6

\section{Discussion}

In general, the theory regarding these emerging markets is substantiated by the results of this study. As predicted, China exhibited considerable tolerance for the questionable behaviours used in this study. The premise that less developed economies are more permissive was borne out as the cultural phenomena of guanxi, Confucian dynamism, and collectivism all focus on personal relationships and the good of the group. As such, Chinese students' responses were in keeping with the idea that questionable behaviours can be justified when they are viewed as beneficial to the community. So, it should not be surprising that the responses tended to fall within the permissive realm. In fact, the average rating for the Chinese students fell on the acceptable side of the scale on eight of the 14 scenarios. One additional action resulted in a mean score only two one-hundredths of a point above the midpoint, thus denoting a bare minimum of disdain for the action. Still, moderately strong condemnation of five actions was documented.

The most accepted action was that of outsourcing labor to a less costly foreign facility. The students most likely understand how China benefits as a site for such actions; thus, they expressed openness to that action. Similarly, the most strongly criticized action was that of exporting unsafe products to countries with lax safety and consumer protection laws. Even though the question was framed from the perspective of China being the exporter, it is conceivable that the students' concern was predicated upon the greater likelihood that China would be the target rather than the source of these dangerous products. Consequently, the mean response of 4.82 indicates that this action is strongly opposed. What is evident is the fact that the Chinese do not unabashedly accept all actions with a caveat emptor philosophy. The range of means from 1.43 to 4.82 on the six-point scale is consistent with the earlier statement that the Chinese can be characterized as possessing a situational ethics mindset, one that represents an uneasy juxtaposition of Confucian values and the emerging market ethic.

The cultural underpinnings also painted a rather bleak picture of South Africa. The results again support the presumption that the ethical predisposition of South African students would be relatively low. Six of the practices were deemed acceptable with two others exhibiting results that fell only marginally on the unacceptable side of the scale. This dichotomy of acceptable and unacceptable actions is consistent with Rossouw's (1997) assertion that the sanctions incurred because of apartheid have led South Africans to accept some business practices that are questionable at best. To many, the benefits justify the actions. As was the case with the Chinese, the harshest criticism came in response to the practice of exporting dangerous products to overseas markets. And also like the Chinese, the most strongly embraced action was that of outsourcing production to a low-cost foreign operation. These results are consistent with the situational perspective of business ethics. Are we likely to be the victim or the beneficiary? It is indeed conceivable, as indicated by Moore and Radloff (1996), that profit motives may usurp social mores and legal statutes, and that South Africans are more than willing to accept that tradeoff. 
In comparing the two countries, the initial literature review provided a hint of what this study would ultimately confirm. The cultural dynamics, coupled with South Africa's status as a comparatively advanced economy, intimated that more stringent ethical standards would be evident in South Africa. There are several ways in which the two countries were compared, yet each provided insight which supported that presumption. At the most fundamental level, the simple means for the scenarios were compared. The South African responses resulted in six of the 14 behaviours being deemed acceptable. Conversely, the Chinese students approved of eight of the behaviours. Simply stated, the Chinese were amenable to more of the questionable actions than were the South Africans. The next method was the comparison of the grand means across the 14 scenarios for the two countries. With a statistically significant difference, the lower grand mean for the Chinese sample $(0=3.12)$ indicates that they are more accepting of the array of questionable behaviours than are the South Africans (0 = 3.49). The final, and perhaps the most compelling, evidence supporting this premise is the results stemming from the t-tests that were performed on each scenario. When compared to each other, the Chinese exhibited significantly more disdain for only one of the actions, whereas the South Africans expressed greater opposition for seven of the 14 behaviours used to evaluate each country's ethical predisposition.

A final point that merits discussion is the relative similarity in regard to the two subsets of rejected behaviours. The subset of the eight that were rejected by the South Africans included all six that were rejected by the Chinese. The two deemed acceptable to the Chinese, that were viewed as unacceptable by the South Africans, were those of comparison advertising and higher retail prices in poorer urban markets (although the means for comparison advertising did not exhibit a statistically significant difference). Therefore, it is appropriate to note that the differences are not as pronounced as they might appear on the surface. The snapshot of today's South Africa may in fact project what the snapshot of China will look like in the foreseeable future as the Chinese economy continues to develop and the market ethic assumes a stronger stature in the Chinese culture. Therefore, it may be just as important to focus on similarities as it is to delineate the differences.

\section{7}

\section{Conclusions}

The snapshot of the Chinese students projects a disconcerting reality. Their ethical predisposition is low. However, there are behaviours for which they exhibit meaningful concern. Thus, we cannot conclude that China is a laissez faire society where anything goes. There is reason to believe that higher ethical standards will accompany the evolution and growth of the Chinese economy. The snapshot of the South African sample is a little more encouraging. Fewer actions were deemed acceptable and the overall measure of ethical predisposition hovered around the midpoint of the rating scale.

The comparison of the two countries documents the fact that South African students possess a stronger ethical predisposition than do their Chinese counterparts. This is supported by the fact that the RSA students exhibited significantly more concern on seven of the 14 scenarios. A higher grand mean for the set of scenarios provides additional evidence that the South African students are less likely to accept breaches of ethical standards.

This research should be deemed a starting point for future efforts in the assessment of these two important countries. The small sample sizes need to be increased. Furthermore, the samples need to be more geographically dispersed so as to attain greater representation of the various subcultures in each country. Still, the results are meaningful. This empirical research is consistent with the theoretical underpinnings. As such, it supports the premise that both countries still have a long way to go before they close the ethics gap between themselves and the more highlydeveloped economies of the world. In order to evaluate this transition, additional research that facilitates the comparison of these two countries with an array of more advanced economies such as Australia, Germany, Japan, and the United States needs to be undertaken. Only then can 
more meaningful conclusions about the presence and the shrinking of the ethics gap noted in a myriad of earlier studies be drawn.

\section{References}

1 AHMED, M.; CHUNG, K. \& EICHENSEHER, J. (2003) "Business students' perceptions of ethics and moral judgment: A cross-cultural study", Journal of Business Ethics, 43: 89-102.

2 ANON (2006a) "Emerging markets", World Economic Prospects Monthly Review (August): 1617.

3 ANON (2006b) "Survey: Emerging at last", The Economist, 380 (8495): 10.

4 ATKINS, R.; CHUNG, J. \& SCHIERITZ, M. (2007) "German plan to help boost bond markets in emerging economies", Financial Times (Feb. 5): 8.

5 BATSON, A, (2006) "As China reins in piracy, some seek faster results: Firms in U.S., E.U. want officials to press Beijing for stiffer enforcement", Wall Street Journal (Nov. 27): A3.

6 BERRELL, M. \& WRATHALL, J. (2007) "Between Chinese culture and the rule of law", Management Research News, 30(1): 57-76.

7 CHEN, R. \& CHEN, C. (2005) "Chinese professional managers and the issue of ethical behaviour", Ivey Business Journal Online, (May/ June): 1-5. Accessed: 25 March 2007.

8 CHEUNG, W. \& PRENDERGAST, G. (2006) "Buyers' perceptions of pirated products in China", Marketing Intelligence \& Planning, 24(5): 446-462.

9 DAILY NEWS (1997) "We're in for a tough one", (Jan. 13): 8.

10 DU, L. \& TANG, T. (2005) "Measurement invariance across gender and major: The love of money among students in the People's Republic of China”, Journal of Business Ethics, 59: 281-293.

11 ENDERLE, G. (2001) "Integrating the ethical dimension into the analytical framework for the reform of state-owned enterprises in China's socialist market economy: A proposal", Journal of Business Ethics, 30: 261-275.

12 FOK, L.; HARTMAN, S. \& KWONG, K, (2005) "A study of differences in business ethical values in Mainland China, the U.S. and Jamaica", Review of Business, 26(1): 21-26.

13 FULLERTON, S. (1993) "The ethical predisposition of our next generation of business and community leaders", Proceedings of the Atlantic Marketing Association, Roberta Good (ed.) (March): 317-323.
14 HE, Q. (1998) China's Pitfall, Mingjing

Chubanche: Hong Kong.

15 HOFSTEDE, G. (1980) Culture's Consequences: Comparing Values, Behaviors, Institutions, and Organizations Across Nations, Sage Publications: Beverly Hills, CA.

16 HOFSTEDE, G. \& BOND, M. (1988) "The Confucius connection: From cultural roots to economic growth", Organizational Dynamics, 16: 5-21.

17 JACKSON, T.; DESHPANDE, D.; JONES, J.; LAU, K.; MATSUNO, K.; NAKUNO, C.; PARK, H.; PIORUNOWSKA-KOKOSZKO, J.; TAKA, I. \& YOSHIHARA, H. (2000) "Making ethical judgments: A cross-cultural management study", Asia Pacific Journal of Management, 17: 443-472.

18 KHERA, I. (2001) "Business ethics East vs. West: Myths and realities", Journal of Business Ethics, 30(1): 29-39.

19 KLEIN, S. (1999) "Marketing norms measurement: An international validation and measurement", Journal of Business Ethics, 18(1): 65-72.

20 LOVETT, S.; SIMMONS, L. \& KALI, R. (1999) "Guanxi versus the market: Ethics and efficiency", Journal of International Business Studies (Second Quarter), 30(2): 231-248.

21 MARTA, J.; SINGHAPAKDI, A. \& HIGGSKLEYN, N. (2001) "Corporate ethical values in South Africa”, Thunderbird International Ethics, 43(6): 755-772.

22 MOORE, R. \& RADLOFF, S. (1996) “Attitudes towards business ethics held by South African students", Journal of Business Ethics, 15(8): 863869.

23 NEALE, L. \& FULLERTON, S. (2008) "Social identity theory and ethical predisposition", $33^{\text {rd }}$ Annual Macromarketing Society Conference, (June) in press.

24 NORTON, L. (2007) "Doubling down on emerging markets”, Barron's (Jan. 1): 87 (1), M11.

25 PEDERSON, M. \& WU, V. (2006), "Business integrity in China", The China Business Review (Jan/Feb): 33(1): 32-36.

26 RAO, Y. \& RANDALL, D. (1991) "Exploring subcultural differences in Hofstede's Value Survey: The case of the Chinese", Asia Pacific Journal of Management, 8(7): 159-173.

27 ROSSOUW, G. (1994a) "Business ethics in developing countries", Journal of Business Ethics, 4(1): 43-51.

28 ROSSOUW, G. (1994b) Business Ethics - A Southern African perspective, Southern Book Publishers: Midrand. 
29 ROSSOUW, G. (1997) "Business ethics in South Africa”, Journal of Business Ethics, 16(14): 15391547.

30 ROSSOUW, G. (2005) "Business ethics and corporate governance in Africa", Business and Society, 44(1): 94-106.

31 ROSSOUW, G.; VAN DER WATT, A. \& MALAN, D. (2002) "Corporate governance in South Africa", Journal of Business Ethics, 37(3): 289-302.

32 SHAFER, W.; FUKUKAWA, K. \& LEE, G. (2006) "Values and the perceived importance of ethics and social responsibility: The U.S. versus China", Journal of Business Ethics, 70: 265-284.

33 SCHLENKER, B. \& FORSYTH, D. (1977) "On the ethics of psychological research", Journal of Personality, 37: 225-252.

34 SINGHAPAKDI, A.; HIGGS-KLEYN, N. \& RAO, C. (1999) "Selected antecedents and components of ethical decision-paking process of American and South African marketers: A crosscultural analysis", International Marketing Review, 16(6): 458-475.

35 SZETO, R.; WRIGHT, P. \& CHENG, E. (2006) "Business networking in the Chinese context: Its role in the formation of guanxi, social capital, and ethical foundations", Management Research News, 29(7): 425-438.

36 TAM, O. (2002) "Ethical issues in the evolution of corporate governance in China", Journal of Business Ethics, 37: 303-320.

37 VAN ZYL, E. \& LAZENBY, K. (1999) "Ethical behaviour in the South African organizational context: Essential and workable", Journal of Business Ethics, 21(1): 15-22.

38 VELASQUEZ, M. (2000) "Globalization and the future of business ethics", Business Ethics Quarterly, 10(1): 343-352.

39 VITELL, S.; NWACHUKWU, S. \& BARNES, J. (1993) "The effects of culture on ethical decisionmaking: An application of Hofstede's Typology", Journal of Business Ethics, 12: 753-760.

40 VOGEL, D. (1992) "The globalization of business ethics: Why America remains distinctive", California Management Review, 35(1): 30-49.

41 WHITCOMB, L.; ERDENER, C. \& LI, C. (1998) "Business ethical values in China and the U.S.", Journal of Business Ethics, 17: 839-852.

42 WONG, Y. \& CHAN, R. (1999) "Relationship marketing in China: Guanxi, favoritism and adaptation", Journal of Business Ethics, 22(2): 107118.

43 WOODBINE, G. (2004) "Moral choice and the declining influence of traditional value orientations within the financial sector of a rapidly developing region of the People's Republic of China”, Journal of Business Ethics, 55: 43-60.

44 WORLD FACTBOOK (2008) www.cia.gov/library/ publications/the-world-factbook/docs/profileguide. html, accessed 24 February 2008.

45 WRIGHT, P.; SZETO, W. \& LEE, S. (2003) "Ethical perceptions in China: the reality of business ethics in an international context", Management Decision, 41(1/2): 180-189. 